\title{
IDENTIDAD DE LOS OTROS EN EL ESQUEMA CIVILIZACIÓN/BARBARIE: Rodolfo Walsh en la actualización del paradigma
}

\author{
Cuando hagamos escándalo y justicia \\ el tiempo habrá pasado en limpio \\ tu prepotencia y tu martirio, hermana. \\ (Eva, María E. Walsh)
}

\section{La cuestión en general}

Todo intento de reconocer la vigencia de la "Barbarie", como un elemento de interpretación de la cultura nacional en la hora actual, pareciera impulsarnos inexorablemente a la visión retrospectiva. Y no puede ser de otra manera si admitimos que vida y literatura se conjugaron en torno al binomio categorizador a partir de la herencia de Sarmiento.

Intentaremos, no obstante, reinstalar la problemática a través del análisis de un fenómeno contemporáneo, que por ser político, obviamente no instaura códigos absolutamente ajenos a la diacronía en la historia nacional, ni en el contexto amplio latinoamericano, pero supone una instancia bastante diferente de la etapa de formación de las nacionalidades, como se considera del siglo XIX.

A mediados de este siglo irrumpe en el país el movimiento liderado por Juan Domingo Perón y desde entonces a hoy mucha letra ha corrido bajo la mano de analistas políticos, investigadores sociales, escritores y críticos literarios. No es nuestro propósito abarcar el considerable espectro de esos múltiples tratamientos, básicamente porque el plano político en sí requiere de una óptica especializada, y porque el recorte que realizamos de ese objeto se centra en las ficcionalizaciones del peronismo.

El punto es que siendo la barbarie el eje de reflexión y el peronismo nuestro propósito habrá que transitar los espacios en que ambas entidades se interceptan. En este sentido lo primero sería despejar la abarcatura del concepto - lexicalizado ya en barbarie- o, en todo caso, sus resemantizaciones ya que la oposición Civilización/Barbarie se remonta al momento de la Conquista - en la cultura hispanoamericana ${ }^{1}$-, aunque es el siglo XIX el escenario intelectual que arquetipiza la polaridad.

\footnotetext{
${ }^{1}$ América como Extremo Occidente, en el sentido en que lo plantea Mignolo (1994) es heredera del constructo barbarie con la implícita relatividad emanada de los límites del Imperio Romano, primero y de la oposición moros y cristianos, después: los aborígenes americanos eran los infieles.
} 
Ni uno ni otro es el ámbito en que peronismo y barbarie se justifiquen como vectores confluyentes, esto si atendemos a la especificidad de la diferencia entre lo que se creyó civilizado durante la Conquista y lo que los pensadores del siglo XIX reforzaron, en términos de etnocentrismo civilizador. ${ }^{2}$ Hay, sin embargo, un gozne entre ambos cortes cronológicos y ese es el que nos interesa focalizar, se trata de las categorías que implican el posicionamiento nosotros/los otros. Un esquema bipolar siempre supone la traslación del eje identitario al plano axiológico. Así, históricamente hubo un polo positivo para el Nosotros y negativo para los otros, ya se trate de Griegos/romanos; Cristianos/moros; Conquistadores/aborígenes o Unitarios/federales (a despecho de una enumeración asimétrica). Nos cabe, entonces, determinar cuáles serán los parámetros de una situacionalidad nada sencilla en el caso de la producción literaria que emerge de una coyuntura pero que indudablemente abreva en el genotexto de la escritura política del subcontinente. ${ }^{3}$ Cuál será el lugar de enunciación del nosotros para encontrar la medida de la barbarie atribuida a los otros, y en términos de qué valores se jerarquizan o contraponen.

El libro de Tzvetan Todorov Nosotros y los otros (1992), considerado por él mismo como una "reflexión sobre la historia", provee interesantes aportes a la dilucidación de las ideologías sustentadoras de las discriminaciones. En un recorrido por el origen de los valores Todorov encuentra que los moralistas franceses del siglo XVII reconocen el peso de la costumbre en la conservación de valores. Es claro que la costumbre tiene una inserción nacional, de allí que etnocentrismo y nacionalismo se asienten sobre el supuesto de que "Lo verdadero se define mediante lo nuestro", lo que consiste en identíficar "nuestros valores" con los valores (1992:25)

A este respecto es válido detenernos en el pensamiento de Montaigne ${ }^{4}$ quien nos acerca más al centro de este planteo introductorio. Para el iniciador del ensayo moderno lo bárbaro no se mide en términos relativos, propone en cambio dos sentidos opuestos: uno histórico y positivo, y otro ético y negativo. Veamos, para Montaigne es bárbaro lo que está próximo a los orígenes y sólo por ello es mejor que lo que sobrevino ("esas naciones me parecen bárbaras...) porque están muy próximas a su ingenuidad original." — dice.

\footnotetext{
${ }^{2}$ Aún con lo contradictorio del alegato sarmientino, por ejemplo cuando enrostra a la Conquista española todos los vicios de una cultura del atraso, al tiempo que vitupera de la raza nativa, la contradicción surge al poner en pie de igualdad conquistadores y conquistados respecto de los disvalores que equivalen a barbarie.

Lo civilizado, en cambio, proviene de otros países europeos (Inglaterra-Francia), pero sobre todo de los Estados Unidos.

${ }^{3} \mathrm{Al}$ tomar en cuenta sólo el subcontinente estamos incurriendo en el error conceptual de abstraernos de todas las implicancias que supone el uso de genotexto (cfr. Kristeva, 1986), se trata simplemente de recortar razonablemente una parcela de las implicaturas concéntricas del Polisistema (Even Zohar, 1972). En el desarrollo seguramente aparecerán las expansiones centrípetas que demanda el tema.

${ }^{4}$ Conviene señalar que en el rastreo del punto de origen de los términos "civilización" y "barbarie", María Rosa Lojo se retrotrae al siglo XVIII (1994:11). Todorov, al remitirse a Montaigne retrocede al XVI; aunque el ensayo en cuestión se titula "Des cannibales", el tratamiento justifica la selección de Todorov. La cita siguiente lo demuestra: "Nada hay de bárbaro y salvaje en la nación. [América] según lo que se me ha informado, sino que cada quien llama barbarie a aquello que no es su usanza" (Montaigne, citado por Todorov, 1992:60).
} 
En un segundo sentido es bárbaro aquello que resulta degradante y cruel, y es así como juzga a la sociedad de su tiempo. A la sazón la cuna de la racionalidad, pero capaz de superar a la sociedad primitiva en "toda especie de barbarie". (Todorov, 1992:62)

Curiosamente en este punto entronca el pre Iluminismo con otros momentos de la reflexión sobre la negatividad y descomposición del Occidente civilizado. Sobran los ejemplos del devaneo intelectual moderno y contemporáneo en torno a los inconfundibles síntomas de deacadencia que se profundizan en la medida en que se expande el poder de Occidente. Al igual que crece el pesimismo gestado en el fracaso de los ideales de la democracia, el progreso y la razón. Es imposible no reconocer a Spengler ${ }^{5}$ en este mea culpa de la civilización, pero de lo que se trata - no es de analizar aquí sus argumentos - es de arribar al estadio en que la antinomia bárbaro/civilizado, se invierte o se neutraliza en el análisis autorreflexivo de una importante ala del pensamiento logocéntrico. ${ }^{6}$

Si en el siglo XVI el bárbaro es el que surge como producto de la conquista-invasión del Nuevo mundo, en el siglo XX parece haber colapsado la civilización en aras de su propio cometido, pues estaba "en [su] esencia [...] el terminar con la barbarie" (Hurbon, 1993:24).

Colapso, decadencia, culpabilidad, narcisismo o como se quiera definir, lo cierto es que lo otro, es decir lo bárbaro terminó por encarnarse en lo uno, en las múltiples formas de los holocaustos que el Occidente, otrora armónico, impuso mimetizándose con lo que supuestamente combatía.

\section{Fusión de texto y contexto ¿una barbarización del discurso literario?}

Para situarnos en el contexto más específico de la literatura que rescata aspectos historicos de una Argentina desgarrada por síntomas de barbarie, en este siglo, hace falta interrumpir la mirada diacrónica en sentido estricto. Retomamos, sin embargo, enclaves temporales que explican la resemantización de la otredad en los discursos que tematizan el peronismo.

Desde luego que a esta altura se impone escindir la realidad socio-cultural argentina del resto del continente, no en términos de política internacional sino de composición racial. Desde un punto de vista político América latina vive a finales del siglo XIX el peligro de la expansión imperialista. No había dejado de padecer el impacto transculturador de la Conquista y evangelización, cuando ya se avecinaba la revitalización de los poderes de Occidente, empeñados en una redistribución neonacional.

\footnotetext{
$5^{5}$ Los juicios sobre Occidente tienen representantes de relevancia en las primeras décadas de este siglo. O. Spengler en La decadencia de Occidente (1918) y S. Freud en Malestar de la cultura (1929) son hitos en la búsqueda de respuestas para los problemas de la civilización. Accedemos a ellos a través de Hurbon Laennec: "Génesis de la barbarie" en El bárbaro imaginario, México, F.C.E., 1993, pp. 23-42.

Por cierto, sin olvidar que Spengler es, en gran medida, el genotexto de E. Martínez Estrada en algunas de sus definiciones (Radiografia de la pampa).

${ }^{6}$ Indudablemente siempre serán muchos más que los que aquí se mencionen, pero nos parece significativo aludir a la Escuela de Frankfort y, por supuesto, a Claude Levi Strauss (Hurbon, 1993:27). En la actualidad más próxima debe agregarse la vigilia ética de Noam Chomski.
} 
Si bien los analistas de los diversos usos de las categorías Civilizacion/Barbarie - sean éstos "occidentales" o americanos- casi siempre incurren en revisar fuentes metropolitanas, es muy auspicioso comprobar cómo se diferencian los estudiosos del tema, identificados con la esencia americana. En un alto porcentaje de tratadistas la remisión obligada es a Sarmiento, pero las adhesiones y rechazos marcan líneas de gran significación a la hora de reconocer la pertenencia del enunciador a la instancia del nosotros. ${ }^{7}$

Es demasiado conocida la posición de Sarmiento y no tiene mayor pertinencia a nuestros fines, salvo la de antecedente del lugar de enunciación de la cultura oficial hasta nuestros días. ${ }^{8}$ En ese sentido apelamos a una cita de Fernández Retamar porque ilustra claramente aspectos con los que coincidimos:

...para Sarmiento "civilización" significa [...] los intereses de las burguesías metropolitanas [...] estigmatiza como integrantes de la "barbarie" desde luego a los indígenas, haciéndose eco de un racismo implacable; pero también a los "gauchos", los llaneros o montoneros mestizos de su región [...] desde luego a los gobernantes latinoamericanos que osaron defender los intereses nacionales y entraron por ello en contradicción con los explotadores europeos... (Fernández Retamar, 1993:213-14)

Con prescindencia explícita de "muertes", "resurrecciones" y "transfiguraciones" del gaucho como fenotipo marginal del siglo pasado, nos proponemos avanzar en la hermeneusis de la barbarie porque el texto elegido para demostrar su vigencia ficcionaliza un episodio de un protagonismo otro, aunque el trasfondo pueda asociarse a rosismo y a otras concomitancias.

Indagando sobre la literaturización del peronismo revisamos el valioso trabajo de R. Borello, pero el autor del texto que nos ocupa escapa a la cronología abarcada por el crítico El peronismo (1943-1955) en la narrativa argentina. Borello aporta, en cambio, una visión global de los posicionamientos de grupos intelectuales, frente a un fenómeno político de tanta incidencia en la vida nacional.

Tanto Borello como Goldar ${ }^{9}$ reconocen el poder de la literatura para figurativizar los hechos, pero sobre todo, para registrar los conflictos de la vida social. Exactamente eso es

${ }^{7}$ Sería notablemente esclarecedor mostrar posturas como la de Fernández Retamar exaltando la línea ininterrumpida Bolívar-Martí (tema en el que trabajamos sistemáticamente) en la configuración ideológica de "nuestra América", pero sería perder de vista el objetivo de nuestro enfoque presente. (Cfr. Algunos usos de civilización y barbarie, 1993).

${ }^{8}$ Pensamos a los intelectuales que entornaron a la revista Sur que bien podrían haber suscrito expresiones como la de Mitre: "Tengo odio a la barbarie popular. La chusma y el pueblo gaucho nos es hostil, mientras haya chiripá no habrá ciudadanos" (citado por Fernández Retamar, 1993:219; subrayamos nosotros).

Claro que por el " 40 la chusma no era precisamente la del gaucho - arquetipo ya reivindicado y convertido en símbolo de lo nacional- sino que empezaba a ser el inmigrante obrero de las fábricas, y después del ' 45 el problema no es el chiripá sino el bombo.

${ }^{9}$ Más que un trabajo de profunda reflexión crítica El peronismo en la literatura de Ernesto Goldar es un valioso registro de toda la literatura inspirada — a veces perpetrada - durante y a partir del peronismo (y hasta el ' 70 ; después de entonces se escribió mucho más). 
lo que logra, como efecto de sentido el cuento de Rodolfo Walsh, que de ahora en más será nuestro objeto preciso de análisis.

Esa mujer ${ }^{10}$ concentra en su brevedad, y en la desnudez de su diálogo muchos de los elementos que la crítica avizora en la vasta producción literaria sobre el peronismo. Según Ernesto Goldar en la literatura - a diferencia de la historia- los episodios "tienen alguien por quien suceden" (1971:12). En efecto, Esa mujer recrea un episodio que pertenece a la historia nacional, pero aún conociéndolo fugazmente, su reconocimiento es privativo de iniciados en la lectura de la elípsis. La estrategia discursiva central de Walsh se asienta en dos registro: en el plano de lo dicho, la recurrencia del sintagma del título como única nominación del personaje por antonomasia; por otro lado convergen en lo no dicho la identidad de los actores y la vacuidad de un diálogo que, por zonas, reproduce la letanía onírica. Fundamentalmente en la construcción del enigma.

Uno y otro registro redundan en un efecto de lectura que puede ser uno solo para quienes asumen que la historia nacional tiene "zonas de silencio", esto es tiempos de proscripción, períodos en que se impone la presencia y el poder de un nosotros que decide sobre la inexistencia o invisibilidad de los otros. Creemos que el cuento de Rodolfo Walsh resuelve magistralmente una cuestión lindera a la genericidad como producto del cruce de "series literarias". Pues lo que esta escritura pone en juego en este relato-cuento ${ }^{11}$ son varias competencias: una existencial y compartida (lector y autor argentinos contemporáneos), la del manejo de la histora nacional en sus tramos claroscuros, y al menos una tercera consistente en la decodificación de los roles como consecuencia de conocer la circunstancia de producción del texto. Logrado ese acercamiento el cuento permite reconocer un terreno en el que convive la polaridad nosotros/los otros, eje de nuestra reflexión.

Siendo coherentes con la premisa de que narrador y autor no son lo mismo, trataremos de hacer abstracción de incluir a Walsh en su carnadura biográfica, sin desconocer que los rasgos de enunciación irán perfilando su situacionalidad, ni perder de vista que algunos datos forman parte de las condiciones de producción, antes mencionadas. Escrito entre el '61 y el '64 Esa mujer constituye una pieza singular en la literatura testimonial de uno de los capítulos de la historia reciente que reedita antecedentes de profanación situados en la barbarie del siglo XIX, y preanuncia la indigna zozobra de los desaparecidos insepultos de la década subsiguiente.

En lo que toca a nuestro tema el capítulo "Evita" hace aportes más generales, pero no incluye a Rodolfo Walsh. Sin embargo el texto y el autor aparecen a propósito de otras consideraciones. En el terreno de las valoraciones conviene destacar que Goldar no emite juicio sobre Esa mujer, lo hace en cambio sobre Operación masacre (1957) y sobre "¿Quién mató a Rosendo?" (1969). Señala que hay entre ambos una involución no literaria sino ideológica de Walsh, pero el nivel de análisis es muy plano para darle crédito (1971:128 y 139).

${ }^{10}$ El cuento se publicó en 1965 en Los oficios terrestres, Bs. As: Jorge Alvarez, pero la versión que manejamos pertenece a Crónicas del pasado, Bs, As: J. Alvarez, 1966. Citaremos siempre de allí.

11 Tal vez más apropidado que acudir a definiciones genéricas convencionales sea apoyarnos en concepciones de escritores contemporáneos porque son termómetro de la relación causa-efecto entre historia y ficción. Es el caso de Ricardo Piglia (cercano a Walsh en la mirada crítica y en el cultivo de la escritura policial) para quien "los contenidos sociales del género [...] pasan [...] por la constitución de la subjetividad. Una subjetividad amenazada [...]" que él ha llamado conciencia paranoica (Clarín, 1991). 
Ahora bien, los rasgos que hacen del texto un claro ejemplo de transposición de la barbarie devienen significantes. Si el modo narrativo se redujese al "coraje civil" que caracteriza su visión del mundo, no tendría demasiado sentido un análisis minucioso del enunciado, bastaría son comprobar que diegéticamente cumple con el pacto historia/ficción y que con ello contribuye a la aprehensión consciente de un deber ser, bastante subcutáneo.

Rodolfo Walsh, autor de Esa mujer — y del resto de su narrativa — va más allá de la instauración de un tipo discursivo que se nutre de la crónica periodística y del cuento policial, crónica que ingresa en la Historia y enigma que traduce un comportamiento bárbaro, sustentando una tradición política que entró en la literatura para no abandonarla.

El relato se apoya en el trípode:

$$
\begin{aligned}
\text { autor }- \text { narrador } & =\text { periodista } \\
\text { coronel } & =\text { interlocutor del periodista }
\end{aligned}
$$

misterio del paradero de un cadáver $=$ esa mujer

Ahora bien ¿en qué o en quién radica la barbarie si el relato abarca sólo un largo diálogo entre entrevistador y entrevistado?

Desde el punto de vista del significado el enigma tiene un antecedente: el cadáver fue robado y su escondite es incierto por dos motivos (tal vez para protegerlo de dos frentes de barbarie):

- ¿Qué querían hacer?

-Fondearla en el río, tirarla desde una avión, quemarla y arrojar los restos por el inodoro, diluirla en ácido. ¡Cuánta basura tiene uno que oír!... (Walsh, 1965:99, subrayamos nosotros)

Lo elusivo de la enunciación no se limita al dato no relevado de la identidad del cadáver - sujeto/objeto disparador de la trama - pero es ahí donde la cooperación del lector aporta su competencia para descifrar cuáles son los sectores confrontados, en torno al enigma. En esa confrontación de los sectores textualizados como "ellos" ¿quiénes son los bárbaros y por qué, si el sujeto que oficia de eje de esa bifurcación de la referencialidad se define como lector de Hegel y ostenta cierto buen gusto en la posesión de objetos de arte?

"Me la tienen jurada". [...] Creen que yo tengo

la culpa. Esos roñosos no saben lo que yo hice por ellos...

[...] Pero ellos no saben lo que querían hacer, esos roñosos no saben nada, y no saben que fui yo quien lo impidió. (98-99, subrayamos nosotros)

Poco a poco el discurso se articula permitiendo llenar las marcas pronominales con identidades: "esos roñosos" son los autores del atentado en la casa del Coronel; los profanadores del cadáver son sus compañeros de armas. Si en ambos bandos hay violencia, una parece 
menos justificada. Los que juran venganza por la profanación de los restos de su reina $=$ madre =santa (como el pueblo peronista concebía a Evita, pero también como está discursivizado por el Coronel) y lo intentan mediante una bomba, es la "pobre gente".

La otra es violencia más perversa, pero no tan gratuita como parece, en realidad profanar y desaparecer el cadáver de esa suerte de diosa pagana para millones de argentinos, era una consigna de la Libertadora. Había que terminar con el culto, conjurar la idolatría, recuperar terreno, procurar el olvido.

Ellos —-"los roñosos", "la pobre gente"- son, entonces, los otros cuando el nosotros se constituye en poder. Nos queda por resolver el lugar de enunciación de los actores visibles.

El yo narrador está investido de mirada objetiva y profesional, busca la información sin más. No obstante, entre el parecer del periodista y el decir del escritor ocurre una revelación:

Algún día (pienso en momentos de ira) iré a buscarla. Ella no significa nada para mí, y sin embargo iré tras el misterio de su muerte [...] si la encuentro, frescas altas olas de cólera, miedo y frustrado amor se alzarán, poderosas, vengativas olas, y por un momento ya no me sentiré solo... (96)

Esta voz en off entra en conjunción con tramos del diálogo que son altamente provocadores, proféticos diremos (si ingresa en el pacto de lectura el triste final del sujeto extratextual como víctima del proceso militar 1976-1983).

-Todos, coronel. Porque en el fondo estamos

todos de acuerdo, ¿no? [...]

-Pero sin remordimientos, coronel. Enarbolan-

do alegremente la bomba y la picana.

¡Salud! [...] (subrayamos nosotros)

Por su parte el actor que consideramos como visagra entre el ellos de los desposeídos de Evita y el ellos que encarna el relevo en el poder, sufre el conflicto de su ambivalencia frente a una situación que lo desborda. Por momentos puede sumarse al ultraje - "y orinarle encima"-, pero también su performance fluctúa entre el decir y el hacer.

-Hice una ceremonia [...] Yo respeto las ideas

[...] yo la voy a enterrar como cristiana. (104)

Se puede leer que el grito final, con el cual el Coronel completa lo que está insinuado varias veces el texto, ${ }^{12}$ remata su lugar pretendidamente histórico (Hegel mediante):

-Es mía [...] Esa mujer es mía. (107)

12 Juzgamos como marcas indiciales muchas de las actitudes del coronel con el cadáver, pero hay un enunciado inconcluso que funciona como antecedente del desenlace:

"Eso le demuestra, ¿eh?. Eso le demuestra".

$\mathrm{La}$ inmediata intervención del narrador lo confirma. 
Sin embargo, no puede ignorarse que está ebrio y que la escritura de Walsh tiene derecho a un gesto final de respeto por el canon genérico: un cuento tiene final sorpresivo.

Por lo demás, hay una evidencia del pronunciamiento del Coronel por la barbarie. Jorge Bracamonte ha reparado en ello a propósito de la "gravitancia equívoca, compleja y contradictoria" que ejerce el caso - como episodio histórico real. Aunque rescata la referencia a Facundo en otra codificación: la de la sexualidad. Veamos:

La gravitancia del cuerpo de Eva Perón se vincula con una interpretación cultural que remite además a elementos primordiales de carácter transexual: "iLa enterré parada, como Facundo porque era un macho!" (Bracamonte, 1993:149)

Para nosotros lo transexual funciona como elemento de identificación. Facundo es históricamente el paradigma de la barbarie, y en la axiología militar el coraje es cosa de machos, por eso haber enterrado a Eva de pie como Facundo supone una valoración, una consustanciación con sus agallas. ¿Dónde queda, entonces, nuestra hipótesis de nosotros/los otros en el anclaje de Argentina de la Revolución Libertadora de 1955?

Quizás sea el momento para retrotraer el planteo inicial, es decir el punto en que la barbarie se relativiza toda vez que se produce la supremacía de un poder sobre otro, sea éste "civilizado" o no. Así, el Peronismo fue un régimen bárbaro (pese a sus mayoritarios resultados electorales), de fuerte analogía con el rosismo, en la perspectiva ideológica de los no complacientes. Simétricamente para Perón y su movimiento "La fuerza es el derecho de las bestias". ${ }^{13}$ El apotegma está tomado de Cicerón pero da título a un libro de Juan Domingo Perón escrito en 1958 y, por supuesto, condena el golpe de Aramburu como un ataque imperdonable a la democracia.

Para concluir rescatamos un aspecto insinuado páginas atrás que tiene que ver con la barbarización del significante. Pese a que los antecedentes de Walsh existen, en tanto el relato policial es ya una práctica discursiva vigente en la década del ' 50 , lo que constituye un cambio es la hibridación llevada a extremos desnaturalizantes de lo literario canónico, es decir lo civilizado e incuestionable. La fusión en la escritura de Walsh es una "barbarización" que empezó en Roberto Arlt en tanto incorpora el ingrediente policial y el registro del lumpen, pero que culmina en él por lo acendrado de su diferencia con el "borgismo" dicho en alusión a la atemporalidad y al tono metafísico de las ficciones de Borges (Ford, 1974:274), pero sobre todo porque en esa línea de la narrativa argentina era muy difícil escapar al epigonismo, dada la consagración del maestro.

Adherimos a Aníbal Ford también en la apreciación de que R. Walsh funde lo policial con lo político y que en su búsqueda consciente de objetivos sociales, accede a una literatura

13 El libro de Perón, como tantos otros escritos por gente del movimiento, debe ser leído con la misma prevención con que se lee a Sebreli en Los deseos imaginarios del peronismo, pues no hay objetividad posible cuando la pertenencia de clase es tan categórica como un intelectual de izquierda (volveremos sobre esta cuestión). 
que es más una "reconstrucción" de los hechos que esencia fictiva. En páginas anteriores (cfr. nota 9) hemos adelantado algo sobre la numerosa producción literaria en torno al personaje Eva Perón, nos interesa aquí detenernos en Tomás Eloy Martínez porque su abordaje da crédito a la nomenclatura que Ford atribuyera a la ficción walshiana en 1974, es decir cuando se podía constatar históricamente la reconstrucción, y estaba permitido usar la palabra al servicio de la verdad de los hechos, en esos temas.

Exhumar el tema después del ' 83 supone nuevos hallazgos y ensambles, así, es muy sorprendente que en 1995 otro periodista-novelador del peronismo reconstruya desde y con Walsh - sin excluir otra infinidad de fuentes - el mismo intrincado capítulo del robo y desaparición del célebre cadáver. Concretamente Martínez retrotrae Esa mujer, ${ }^{14}$ como el primer testimonio édito del hecho (producido después de diez largos años de silencio). Luego cuenta un encuentro con $\mathrm{R}$. Walsh en París, cuyo diálogo intertextualiza aspectos del cuento original.

Convocamos estos datos sólo a instancias de una homología, ¿es el tema el que ha dado lugar a una escritura deconstructiva de lo literario canónico y, simétricamente, reconstructiva de los hechos?. Por cierto que el interrogante no se resuelve aquí - porque lo de canónico hoy es una incógnita más-, pero en todo caso es sugestivo el avance de la barbarie: de lo innominado - esa mujer - al centro absoluto de la cultura de masas. En lo que va de este año se han reeditado y lanzado tantas publicaciones sobre Eva Perón como escándalo ha suscitado la filmación de A. Parker, por no hablar de toda suerte de remates y otras bastardías.

Lo literario sobre el tema, en consecuencia, se convierte en un fenómeno más de esa masificación, habrá que aguardar el impacto en el terreno académico para juzgar los giros en un sentido o en otro.

\section{Bibliografía}

BOREllo, Rodolfo (1991): El peronismo (1943-1955) en la narrativa argentina, Ottawa, Dovehouse ed.

BRACAMONTE, Jorge (1993): Rodolfo Walsh y "Esa mujer": la búsqueda imposible y lo proferible en Actas del VII Congreso Nacional de Literatura Argentina, pp. 147-152.

Coseriu, Eugenio (1987): "Lenguaje y política" en Alvar: El lenguaje político, Madrid, Elbert, ICI.

Fernández Retamar, R. (1993): Algunos usos de civilización y barbarie, Bs. As., Buena Letra.

\footnotetext{
${ }^{14}$ Desde luego que nos referimos a la novela Santa Evita (1995) que documenta valiéndose de toda la competencia lectora y periodística de un investigador incuestionable de la vida y de la política de la pareja Perón-Eva. Su texto rescata gran parte de lo escrito por los opositores y lo funde en una curiosa amalgama (pero su análisis es objeto de un papel en ejecución). A nuestros fines actuales diremos que Walsh está textualizado en pg. 14 de la novela y más ampliamente en el capítulo 13 "Pocas horas antes de mi partida", pg. $301 \mathrm{sgs.}$
} 
Fernández Retamar, R. (1973): Calibán. Apuntes sobre la cultura de Nuestra América, Bs. As., Ed. La Pléyade.

FORD, Aníbal (1974): "Walsh: la reconstrucción de los hechos" en Laforgue (Comp.):

Nueva novela latinoamericana 2. La narrativa argentina actual, Bs. As., Freeland. GOLDAR, Ernesto (1971): El peronismo en la literatura argentina, Bs. As., Freeland. Hurbon, Laennec (1993): El bárbaro imaginario, México, F.C.E.

Lojo, María Rosa (1994): La barbarie en la narrativa argentina siglo XIX, Bs. AS., Corregidor.

Martínez, Tomás E. (1994): Santa Evita, Bs. As., Biblioteca del Sur-Planeta.

MAYER, Marcos (1994): Prólogo a El Peronismo. Historia de una pasión argentina, Bs. As., Ed. I.M.F.C.

MIGNOLO, Walter (1994): "Occidentalización, Imperialismo, Globalización: herencias coloniales y teorias poscoloniales", Conferencia II Encuentro Internacional sobre teorías y prácticas críticas, Univ. Nacional de Cuyo.

Perón, Juan D.: (1958): La fuerza es el derecho de las bestias, Montevideo, Cicerón. PIGLIA, Ricardo (1991): "La ficción paranoica" en Cultura y Nación, Clarín, 10/X. Sebreli, Juan José (1983): Los deseos imaginarios del Peronismo, Bs. As., Legasa. TODOROV, Tzvetan (1991): Nosotros y los otros. Reflexiones sobre la diversidad humana, México, Siglo XXI.

\section{IDENTITETA DRUGIH V SHEMI CIVILIZACIJA/ BARBARSTVO: RODOLFO WALSH IN POSODOBITEV PARADIGME}

Argentinsko življenje in argentinska književnost se že od Sarmienta dalje vrtita okoli pojmov civilizacija/barbarstvo in mi/drugi. To dihotomijo je avtorica članka prenesla $v$ današnji čas in $v$ argentinsko stvarnost dvajsetega stoletja ter $v$ ta okvir umestila kratko zgodbo argentinskega pisca Rodolfa Walsha Esa mujer (Tista ženska). Zgodba je bila napisana med letoma 1961 in 1964 in je eno od neštetih besedil, ki so jih o peronizmu pisali politični analitiki, sociologi, pisatelji, literarni kritiki. Besedilo je pričevanje zgodovinskega obdobja in izraz pomena peronizma, ki je močno zaznamoval Argentino. Avtorica Amelia Royo se ob Walshovi kratki zgodbi, ki govori o skrivnostnem izginotju Evitinega trupla - ta motiv je kasneje v svojem romanu Santa Evita uporabil Tomás Eloy Martínez -, sprašuje, kaj je barbarstvo in kaj civilizacija, kdo so naši in kdo oni drugi. 